\title{
A RECESSIVE LETHAL SUPER-SUPPRESSOR MUTATION IN YEAST AND OTHER $\Psi$ PHENOMENA
}

\author{
B. S. COX \\ Botany School, South Parks Road, Oxford
}

Received 12.v.70

\section{INTRODUCTION}

SUPER-SUPPRESSOR mutations are readily isolated in certain auxotrophic strains of yeast by selecting for prototrophic variants. They arise spontaneously or after treatment with mutagens (Hawthorne and Mortimer, 1963; Hawthorne, 1969b; Inge-Vechtomov, 1965). Since, often, they are dominant, they can as readily be found in diploid as in haploid auxotrophs. All the evidence suggests that they act, as do the better-known amber and ochre suppressors in bacteria, through the misreading of mutant nonsense codons by means of altered amino-acid-accepting transfer RNA species (Gilmore and Mortimer, I966; Gilmore, Stewart and Sherman, 1968).

Among a number of suppressors of adenine requirement arising in a hetero-allelic adenine-requiring diploid used in this laboratory was one, $S_{Q_{2}}$ which, in a tetrad analysis of the diploid strain, gave the results summarised in tables 1 and 2. Four facts stand out. First, a recessive lethal mutation

TABLE 1

The pattern of survival of spores in tetrads of the diploid prototroph $\mathrm{Q} 2$. The tetrads are classed according to the number of spores which germinated to form viable cells. Asci were dissected on $Y C$ or $Y \mathcal{N B}$ medium and germinated at various temperatures, as shown

\begin{tabular}{|c|c|c|c|c|c|c|c|c|c|}
\hline \multirow{2}{*}{\multicolumn{2}{|c|}{$\begin{array}{l}\text { Temperature } \\
\text { and } \\
\text { medium }\end{array}$}} & \multicolumn{5}{|c|}{$\begin{array}{l}\text { Number of tetrads in which } \\
\text { so many spores germinated }\end{array}$} & \multirow{2}{*}{$\begin{array}{l}\text { Percentage } \\
\text { germination }\end{array}$} & \multicolumn{2}{|c|}{ Number of spores } \\
\hline & & 4 & 3 & 2 & 1 & $\overrightarrow{0}$ & & $a d^{-}$ & $A D^{+}$ \\
\hline $20^{\circ} \mathrm{C}$. & YC & 0 & 0 & 9 & 1 & 0 & 48 & 19 & 0 \\
\hline $25^{\circ} \mathrm{C}$. & $\mathrm{YC}$ & 0 & 0 & 10 & 0 & 0 & 50 & 20 & 0 \\
\hline $28^{\circ} \mathrm{C}$. & YC & 0 & 0 & 56 & 1 & 0 & 50 & 113 & 0 \\
\hline $34^{\circ} \mathrm{C}$. & YC & 0 & 0 & 8 & 1 & 0 & 47 & 17 & 0 \\
\hline $37^{\circ} \mathrm{C}$. & $\mathrm{YC}$ & 0 & 0 & 8 & 0 & 0 & 50 & 16 & 0 \\
\hline $37^{\circ} \mathrm{C}$. & YNB & 0 & 0 & 9 & 1 & 0 & 48 & 19 & 0 \\
\hline Total & & 0 & 0 & 100 & 4 & 0 & 49 & 204 & 0 \\
\hline
\end{tabular}

is segregating, since, in a majority of tetrads dissected, only two spores germinated to form viable colonies (table I). Secondly, the adenine independence of the diploid is due to a suppressor mutation, since both alleles of the $a d_{2}$ locus segregate out in the haploid progeny. Thirdly, it is clear that the lethal is either identical with or very closely linked to the mutation causing suppression of adenine requirement in the diploids, since none of the segregants is adenine independent. Finally, the lethal mutation is centromere-linked: the digenic tetrad types formed by the segregation of this and of the tightly $c$-linked $t r_{1}$ marker (Hawthorne and Mortimer, 1960), are fifty-nine ditypes and eight tetratypes. The following is an account of a genetic analysis of this behaviour. 


\section{Materials AND methods}

(i) Strains

1. $S_{Q_{2}}$ arose in a diploid of genotype:

$$
2 n=\frac{a}{\alpha} \frac{m e_{2}}{+} \frac{a d_{2,1}^{o}}{a d_{2, c}} \frac{h i_{8} s e_{1}}{++} \frac{t r_{1,1}}{+} .
$$

The adenine-independent revertant of this diploid was named $Q 2$. The $a d_{2, c}$ and $s e_{1}$ markers were isolated in this laboratory. All the other markers originate in strains provided by Dr D. C. Hawthorne and Dr R. K. Mortimer.

2. Other markers used in this study were derived as follows: $h i_{5,2}^{0} ; l y_{1,1}^{0}$ and $\arg _{4,23}$ from JM32 and $h i_{2,1}$ from S723C, both provided by Dr R. K.

TABLE 2

The segregation of the lethal phenotype in relation to the other markers in the diploid. Ditype halftetrads are of two kinds: either both spore-cultures are wild-type or both are mutant $(+,+$ or $-,-)$. In tetratype half-tetrads, one of the two surviving spores is wild-type, the other mutant $(+,-)$. Except for the segregation of mating-type, the results are given from sixty-seven tetrads analysed. The figures shown in the last line are those expected from a random assortment of a lethal gene and a marker and, in the last column, the probability that each marker so assorts is calculated from the $\chi^{2}$ value using these figures

\begin{tabular}{|c|c|c|c|c|c|c|}
\hline \multirow[b]{2}{*}{ Marker } & \multicolumn{3}{|c|}{ Number of half-tetrads } & & & \\
\hline & $\begin{array}{c}+,+ \\
\text { or } a d_{2, c}, a d_{2, c} \\
\text { or } a, a\end{array}$ & $\begin{array}{c}-,- \\
a d_{2}^{o}, 1, a d_{2}^{o}, 1 \\
\alpha, \alpha\end{array}$ & $\begin{array}{c}+,- \\
a d_{2}, c, a d_{2}^{0}, 1 \\
a, \alpha\end{array}$ & Total & $\chi^{2}$ & $\mathrm{P}$ \\
\hline$a / \alpha$ & 14 & 9 & 13 & 36 & $17 \cdot 1$ & $<0.01$ \\
\hline$a d_{2}$ & 9 & 6 & 52 & 67 & $2 \cdot 87$ & $0 \cdot 25$ \\
\hline$h i_{8}$ & 17 & 7 & 43 & 67 & $4 \cdot 66$ & $0 \cdot 10$ \\
\hline$s e_{1}$ & 13 & 10 & 44 & 67 & $0 \cdot 43$ & $0 \cdot 80$ \\
\hline$m e_{2}$ & 18 & 8 & 41 & 67 & $5 \cdot 38$ & 0.07 \\
\hline $\operatorname{tr}_{1}$ & 30 & 29 & 8 & 67 & $90 \cdot 30$ & $\ll 0.01$ \\
\hline Expected & $11 \cdot 17$ & $11 \cdot 17$ & $44 \cdot 67$ & $67 \cdot 01$ & & \\
\hline
\end{tabular}

Mortimer; $S_{D}$ from X1687-20D, provided by Dr R. A. Gilmore. It is allelic with $S_{11}$ in Hawthorne and Mortimer's classification (1968).

3. Various other super-suppressor mutations are briefly described. They. were also provided by Dr R. A. Gilmore.

The mutations designated $a d_{2,1}^{o} ; h i_{5,2}^{\circ}$ and $l y_{1,1}^{o}$ are suppressible by supersuppressors, and Hawthorne $(1969 a, b)$ reports that they are due to mutations to an ochre (UAA) codon. $t r_{1,1}$ is suppressible by another class of supersuppressors and is said to be due to an amber (UAG) mutation; it is, however, not suppressible by any of the suppressors described here. As an aid to following the discussions and descriptions, the three "ochre "suppressible alleles will be identified throughout the text by a superscript "o".

The remaining symbols used are the conventional ones and are described in the 1966 supplement to the Microbial Genetics Bulletin. " $S$ " indicates a dominant suppressor, and in this paper always designates a super-suppressor. Different super-suppressors are distinguished by subscripts.

Super-suppressors have been classified on the basis of their patterns of suppression (Hawthorne and Mortimer, 1968; Hawthorne, 1969a, $b$; Gilmore, 1966, 1967). In this paper, the classes referred to are those 
defined by Gilmore since, where comparisons have been made, they were with his suppressors.

Mutations at the $a d_{2}$ locus confer a red coloration on the strains. Suppressed $a d_{2}$ mutations do not, and the strains are the normal white colour.

\section{(ii) Media}

YC, yeast complete (Cox and Bevan, 1962), gelled or not with agar, is the normal growth medium.

YNB is used as a minimal medium, with growth-factor supplements as required. It is made from Difco yeast nitrogen base without amino acids, with 2 per cent. dextrose and solidified with agar.

The sporulation medium used is that described by Hurst and Fogel (1964).

\section{(iii) Culture methods}

Standard bacteriological techniques are used in plating and subculturing. Single-cell isolations and tetrad dissection are carried out with a micromanipulator. Asci are prepared for dissection by treatment with snail enzyme (Johnston and Mortimer, 1959). Matings are performed by isolating zygote figures with a micromanipulator from mixtures of cells of opposite mating-types. Occasionally, such mating-mixtures are directly sporulated.

\section{Nomenclature}

Example: $198 / 6 c$ is the culture which grew from the third spore (numbered $a-d$ ) in the sixth tetrad dissected from diploid 198. The nomenclature of the other strains follows the same practice.

\section{EXPERIMENTS \\ (i) Rescue matings}

The close $c$-linkage of the lethal mutation suggests that the lethality arises from a centromere defect which, at the time of meiosis or after causes misdivision, specifically, perhaps, a non-disjunction of one chromosome so that inviable nullisomic or disomic haploid cells are formed. The first step, then, is to test whether the lethal genome can be recovered and if it can, whether it is intact, or aneuploid. It is also recorded (Mortimer and Hawthorne, 1966) that the super-suppressor $S_{D}$ is closely c-linked on chromosome VI.

It was decided to cross a lethal-carrying strain with two strains. One was of genotype: $228 / 3 d=\alpha, a d_{2,1}^{0}, h i_{2,1} ; h i_{2}$ being a $c$-linked marker on chromosome VI (Mortimer and Hawthorne, 1966). The other strain carried super-suppressible markers and was of genotype: $198 / 6 c=a, a d_{2,1}^{0}$, $h i_{5,2}^{\circ}, \operatorname{ly}_{1,1}^{o}, \arg _{4,23}, t r_{1,1}$.

To carry out a genetic analysis with a gene fatal to any haploid cell carrying it presents difficulties. However, a process of spore rescue by mating proved successful. A set of tetrads of the $S_{Q_{2}}$ diploid was dissected and the spores moved to marked positions on a $\mathrm{YG}$ agar plate. A single haploid cell of the chosen rescuer strain was placed in contact with each spore in each tetrad. The paired cells were observed at intervals and a record kept 
of the zygotes formed. As soon as the two mating figures in each tetrad could be identified, the other two pairs of cells (which must have been pairs of identical mating-type) were separated so that spore-cultures of each tetrad could be recovered uncontaminated by the rescuer strain.

Only one kind of tetrad can be rescued as a complete tetrad by this technique-that in which the lethal mutation segregates in coupling with a mating-type allele complementary to that of the rescuer strain. The technique is illustrated in fig. 1 .

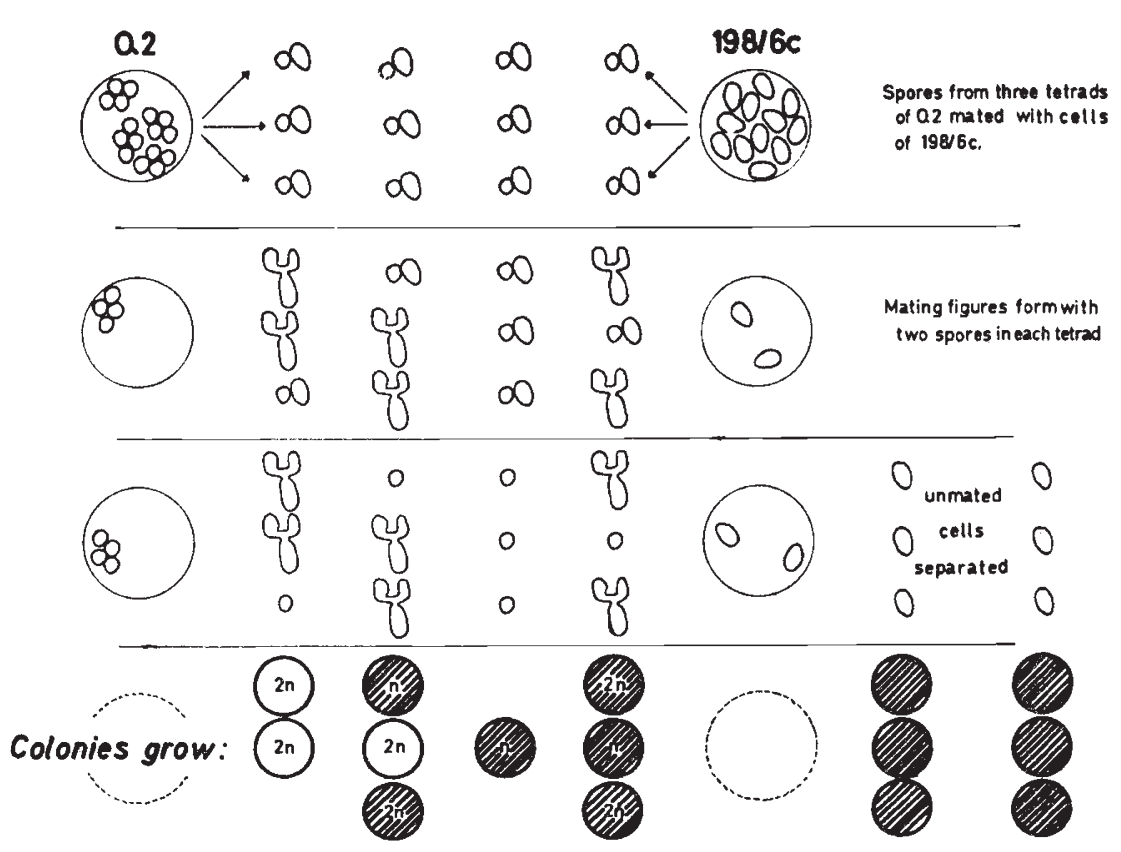

Fig. 1.- Rescue by mating. The figure shows three tetrads of the diploid $Q 2$ dissected out and each spore paired with a cell from a culture of haploid strain 198/6c. The genotypes of the two strains are given in table 3, section A. The cells at two subsequent stages of the operation, and finally the colonies that grow from them, are shown. Adenine-requiring colonies are shown hatched, and the ploidy of the cultures is indicated.

Two such whole tetrads and ten other zygotes were recovered from the crosses with 198/6c and a number of zygotes from the crosses with $228 / 3 d$. Recovery was incomplete: there were not always two zygote figures formed in every tetrad.

Four adenine-independent (suppressed) zygote cultures, two from each set of crosses were sporulated and tetrads dissected. The germination in these tetrads is indicated in the general table of germinations (table 4, lines 1-4). It is clear that the lethal mutation is segregating. With two exceptions, all the surviving cultures were adenine requirers.

A further spore rescue operation was performed with the rescued zygote $Z 6$, using $198 / 6 c$ again as the rescuer strain. Two whole tetrads were recovered, together with a number of zygotes. A summary of the rescue operations is given in table 3. 
TABLE 3

The phenotypes of strains formed by mating spores of $\mathrm{S}_{\mathbf{Q}_{2}}$-carrying diploids with $198 / 6 \mathrm{c}$. The segregation of markers in four complete tetrads is shown in this table. The first two tetrads are from the diploid Q2, the second two from $\mathrm{Z6}$. The third part of the table summarises the important phenotypes of all the zygotes recovered in these experiments

(A)

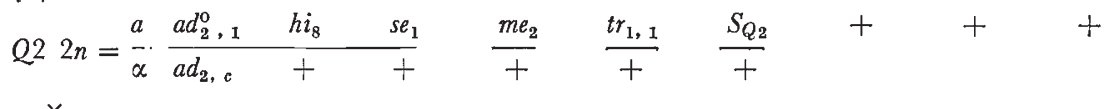
$\times$

$198 / 6 c=a a d_{2,1}^{0}+\quad+\quad t r_{1,1}+h i_{5,2}^{0} l y_{1,1}^{0} a r_{4,23}$

Phenotype

Tetrad I m.t. ADE HIS SER MET TRY

b

c

d

$\begin{array}{cccccc}a & - & + & + & + & - \\ a & - & - & - & - & - \\ \text { zygote } & + & + & + & + & + \\ \text { zygote } & & & -m & +\end{array}$

Tetrad II

$\begin{array}{ccccccc}\mathrm{a} & a & - & + & - & + & + \\ \mathrm{b} & a & - & - & + & - & + \\ \mathrm{c} & \text { zygote } & + & + & + & + & - \\ \mathrm{d} & \text { zygote } & + & + & + & + & -\end{array}$

Also ten other zygotes, $Z 4-Z 13$. Six were $A D^{+}, 4, a d^{-}$. Tetrads of $Z 4$ and $Z 6$ were dissected with the results shown in table 4 , lines 1 and 2. $Z 6$ tetrads were also used in a rescue-mating experiment from which two complete tetrads were recovered (table $3(B)$ ).

$(B)$

\begin{tabular}{|c|c|c|c|c|c|c|}
\hline$Z 62 n=\frac{a}{\alpha}$ & $\frac{a d_{2,1}^{0}}{a d_{2, c}}$ & $\frac{h i_{5}^{0}, 2}{+}$ & $\frac{l y_{1,1}^{0}}{+}$ & $\frac{a r_{4,23}}{+}$ & $\frac{t r_{1,1}}{+}$ & $\frac{+}{S_{Q_{2}}}$ \\
\hline$x$ & & & & & & \\
\hline $198 / 6 c=a$ & $a d_{2,1}^{0}$ & $h i_{5,2}^{0}$ & $l y_{1,1}^{0}$ & $a r_{4,23}$ & $t r_{1,1}$ & + \\
\hline & \multicolumn{6}{|c|}{ Phenotype } \\
\hline Tetrad III & m.t. & $\mathrm{ADE}$ & HIS & LYS & ARG & TRY \\
\hline a & zygote & + & + & + & - & not tested \\
\hline b & zygote & + & + & + & - & not tested \\
\hline c & $a$ & - & + & - & + & not tested \\
\hline d & $a$ & - & - & - & + & not tested \\
\hline
\end{tabular}

\section{Tetrad IV}

$\begin{array}{ccccccc}\text { a } & a & - & - & + & - & - \\ \text { b } & \text { zygote } & + & + & + & - & + \\ \text { c } & \text { zygote } & + & + & + & + & + \\ \mathrm{d} & a & - & - & - & + & -\end{array}$

(C) Summarised results

Total tetrads dissected $(Q 2$ and $Z 6 \times 198 / 6 c) \quad 30$

Number of zygotes formed with $198 / 6 c$ cells 38

$\begin{array}{ll}\text { Number of adenine-independent zygotes } & 21\end{array}$

$\begin{array}{ll}\text { Number of adenine-dependent zygotes } & 17\end{array}$

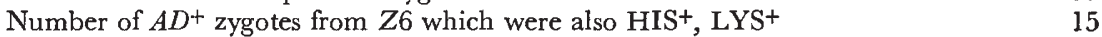

Number of $A D^{+}$zygotes from $Z 6$ which required histidine or lysine $\quad 0$ 
From these results we may draw several conclusions.

1. The suppressor of adenine requirement can be recovered from the spores of diploids in which adenine requirement is suppressed. In the four whole tetrads rescued, two of the spores carried the suppressor and the other two did not. Among the remaining diploids arising from zygote rescues, roughly equal numbers were requirers of adenine or adenine independent. As far as it can be judged from this result, therefore, the suppressor segregates as a mendelian factor. There is no regular non-disjunction or centromere malfunction of the chromosome on which it is situated.

2. The lethal mutation which is closely linked to it is recovered at the same time. This is shown by the six rescued adenine independent $\left(A D^{+}\right)$ diploids which were analysed further. Segregation in them was almost invariably 2 ad-: 2 dead spore cultures (table 4, lines 1-6).

3. The tetrad analysis of these diploids showed that other markers from both parents always segregated. It must be concluded that these adenineindependent diploids arise from zygotes formed between the rescuer strain and a suppressor-carrying spore from the diploid, which would otherwise have died.

4. The suppressor of adenine requirement is a super-suppressor. In the rescued diploid $Z 6$, three super-suppressible alleles are segregating: $a d_{2,1}^{0}$, $h i_{5,2}^{o}$ and $l y_{1,1}^{o}$. Rescue matings of spores of $Z^{6}$ with $198 / 6 c$ should often, therefore, be homozygous for one or more of these alleles. Tests for requirements of all the zygotes isolated show that all adenine-independent zygotes are also histidine and lysine independent, whereas adenine requiring zygotes may be requirers for either of these growth factors. Furthermore, the analysis of the whole tetrads of zygote $Z 6$ shows that one of the rescued zygotes in tetrad I $(Z 6 / 1 a$ or $1 b \times 198 / 6 c)$ must be homozygous for $h i_{5,2}^{\circ}$ and one in tetrad 2 must be homozygous for $l y_{1,1}^{0}$ (table 3 ). All four rescued zygotes in these two tetrads are, nevertheless, independent of lysine, histidine and adenine.

5. The lethal mutation is on chromosome VI. The zygotes formed by rescue matings of spores from $S_{Q_{2}}$ with the rescuer strain $228 / 3 d$ would be expected to be of genotype:

$$
2 n=\frac{a}{\alpha} \frac{h i_{2,1}+}{+l e t^{*}} \frac{a d_{2,1}^{o} h i_{8}^{ \pm} s e_{1}^{ \pm}}{a d_{2,1}^{o}++} \frac{m e_{2}^{ \pm}}{+} \frac{t r_{1}^{ \pm}}{+} .
$$

Thus the segregation of $h i_{2,1}$ and the lethal mutation would form halftetrads as follows:

$\begin{array}{cccc} & \text { parental } & \text { non-parental } & \text { tetratype } \\ & h i_{2}+ & h i_{2} \text { let } & h i_{2} \text { let } \\ h i_{2}+ & h i_{2} \text { let } & h i_{2}+ \\ & + \text { let } & +++ & + \text { let } \\ & + \text { let } & +++ & +{ }^{+}+ \\ \text {giving } & 2 h i^{-}: 0 & 2 H I^{+}: 0 & 1 H I^{+}: 1 h i^{--}: 0\end{array}$

The numbers of each type observed in these two crosses, and in another in which both genes were segregating were: parental, 15; non-parental, 1; tetratype, 18. (Strain 233: $7 P, 0 \mathcal{N}, 5 T$; strain 234: $4 P, I \mathcal{N}, 12 T$; strain 243: $4 P, 0 \mathcal{N}, 1 \mathcal{T})$. This is taken to indicate linkage of $h i_{2}$ and the $c$-linked lethal mutation $\left(\chi_{P=N}^{2}>12 ; p \ll 0.01\right)$.

$$
\text { * let }=\text { lethal gene. }
$$


TABLE 4

The survival in tetrads from various diploids heterozygous for the suppressor mutation, $\mathrm{S}_{Q_{2}}$

Diploid

no.

1. $Z 4$

2. $Z 6$

3. 233

4. 234

5. 241

6. 242

7. 244

8. 243

9. 356

10. 272

11. 273

12. 276

13. 277

14. 278

15. -

16. -

17. -

18.-

19.

20. -

21.-

22. -

23. -

24.

25.

26. -

27. -

28.-

29.-

30.-

31. 318

32. 319

33. 323

34. 326

35. 324
Mated strains

Q2 spore $\times 198 / 6 c$

Q2 spore $\times 198 / 6 c$

$Q 2$ spore $\times 228 / 3 d$

$Q 2$ spore $\times 228 / 3 d$

$Z 6$ spore $1 b \times 198 / 6 c$

$Z 6$ spore $1 a \times 198 / 6 c$

$233 / 4 b \times 228 / 1 d$

$234 / 17 a \times 228 / 1 d$

$234 / 17 a \times 233 / 12 b$

$249 / 5 b \times 170 / 2 c W\left(\psi^{+}\right)$

$249 / 5 b \times 170 / 2 c R \quad\left(\psi^{-}\right)$

$249 / 5 a \times 172 / 9 b W\left(\psi^{+}\right)$

$249 / 5 a \times 172 / 9 b R 1\left(\psi^{-}\right)$

$249 / 5 a \times 172 / 9 b R 2\left(\psi^{-}\right)$

$367 / 10 c \times 376 / 1 a$

$367 / 2 c \times 376 / 1 b$

$367 / 10 c \times 376 / 1 c$

$367 / 2 c \times 376 / 1 d$

$367 / 2 c \times 376 / 2 a$

$367 / 10 c \times 376 / 2 b$

$367 / 10 c \times 376 / 2 c$

$367 / 2 c \times 376 / 2 d$

$367 / 2 c \times 376 / 7 a$

$367 / 10 c \times 376 / 7 b$

$367 / 2 c \times 376 / 7 c$

$367 / 10 c \times 376 / 7 d$

$367 / 10 c \times 197 / 2 c \quad\left(\psi^{-}\right)$

$367 / 10 c \times a d_{2}^{o}, 1, a\left(\psi^{+}\right)$

$367 / 2 c \times a d_{2}^{0}, 1, \alpha \quad\left(\psi^{+}\right)$

$367 / 2 c \times 197 / 2 d$

$S_{D} \times 193 / 1 a$

$S_{D} \times 172 / 9 b R 1$

$S_{D} \times 172 / 9 b R 2$

$S_{D} \times 172 / 9 b \mathrm{~W}$

$S_{D} \times 151 / 5 c$
Percentage

germination

50

45

29

49

18

43

55

35

31

53

100

58

78

93

30

45

50
50

50
0

50

48
68

55

45

38

43

83

43

30

90

88

80

93

50
Number of tetrads in which so many spores grew

Notes-1. In Column 2, the strain carrying $S_{Q_{2}}$ is given first.

2. ${ }^{a}$ All $a d^{-}$.

${ }^{b}$ In two of these there were micro-colonies which could not be subcultured. The third was $2 a d^{-}: 1 A D^{+}$. The $A D^{+}$is $234 / 17 a$ (see 11.8 and 9 and text).

- $2 a d^{-}: 1 A D^{+}$. Not analysed further.

d $2=$ all $a d^{-} . \quad 1=2 a^{-}: 1 A D^{+}$.

- $S_{Q_{2}}$ did not segregate in these tetrads.

$1 \mathrm{l}=1 A D^{+}: 1 a d^{-}$.

g 2 large colonies, 1 or 2 minute colonies in each tetrad.

${ }^{h} 2 A D^{+}: 2 a d^{-}$.

i 2 large: 2 minute in one tetrad.

j 2 large: 2 minute.

\section{(ii) The way of death}

Sets of asci were dissected, the spores moved to marked positions on agar plates and the plates incubated at various temperatures for 4 to 5 days, in which time two spores in most tetrads had grown, as is usual, to form 
colonies of $2 \mathrm{~mm}$. or more in diameter. The non-viable spores were inspected microscopically. A number of spores had germinated and divided, some often enough to form microcolonies. Most of them remained undivided or formed fewer than ten cells before growth ceased. Most of the single cells and those in the very small groups were lysed or abnormal in appearance. Cells in the larger microcolonies looked healthier on the whole, if somewhat variable in size. However, all attempts to subculture these microcolonies by re-streaking them on fresh $\mathrm{YC}$ agar plates failed. It is clear that whatever causes death in these strains, its effects may be immediate or be delayed for a few cell generations. It was also clear that the lethal effects are not modified by differences in the temperature at which the spores are germinated (see table 1). Table 5 shows the numbers of cells which grew from lethalcarrying spores in one set of tetrads.

\section{TABLE 5}

The number of cells formed by each spore in a set of tetrads dissected from $\mathrm{Q} 2$ and germinated at $25^{\circ} \mathrm{C}$. The colonies were spread and counted after five days' incubation. Normal sized colonies were not counted, and are recorded in the table as ' + ',

Tetrad
no.
1
2
3
4
5
6
7
8
9
10

\begin{tabular}{rccc}
\multicolumn{4}{c}{ Spore no. } \\
\hline$a$ & $b$ & $c$ & $d$ \\
71 & + & + & 1 \\
308 & 129 & + & + \\
7 & + & + & 37 \\
+ & 9 & 13 & + \\
13 & + & 44 & + \\
296 & 2 & + & + \\
+ & 344 & + & 50 \\
22 & + & 8 & + \\
15 & + & + & 1 \\
+ & 29 & 51 & +
\end{tabular}

(iii) The viable suppressed haploid strains

Tetrads from a diploid in which a lethal mutation is segregating should never give rise to more than two viable cultures. However, among the two hundred such tetrads so far described, there were a few found in which three or four viable cultures were recovered. In some of these, all the cultures were adenine dependent $\left(a d^{-}\right)$and they could therefore be ascribed to irregular segregation or the occasional contamination of one tetrad by spores from another, which is liable to occur when dissecting yeast asci after cytase treatment. There was one tetrad, however, in which one of the three cultures obtained was adenine independent while the other two were adenine requirers. This culture was 234/17a. It seemed likely to be due to a back-mutation or conversion of the lethal mutation which did not affect the super-suppressor. There were two other cultures which were adenine independent. These cultures were: $233 / 4 b$, one of two spores germinating in a tetrad and $Q 2 / 13 a$, also one of two spores germinating. These may have represented the results of recombination between the super-suppressor and lethal mutations. Other explanations, including back-mutation of the adenine mutation or, a second suppressor mutation and irregular segregation, were possible, so the first crosses were performed with a strain wild-type for $a d_{2}\left(\mathrm{AD}_{2}^{+}\right)$.

One of the adenine-independent cultures, $Q 2 / 13 a$, failed to mate with 
any haploid tried. Although it also failed to sporulate, this may indicate that it was a diploid contaminant. In any case, no further analysis could be carried out. The other two cultures arose among the tetrads dissected from the rescues of $Q 2$ spores by mating with 228/3d (table 4, lines 3 and 4). Both were crossed with $228 / 1 d=\alpha, h i_{2,1}, t r_{1,1}$, and asci dissected. The germination of the spores is shown in table 4, lines 7 and 8 . In two of the twenty tetrads, three cultures grew, but in the rest, only two or fewer survived. Among the cultures scored from cross $233 / 4 b \times 228 / 1 d$, ten were adenine requirers and ten adenine independent. This segregation pattern is consistent with what would be expected if a lethal mutation was segregating linked to a suppressor of adenine requirement. (That the adenine independence in $234 / 17 a$ and $233 / 4 b$ is due to a suppressor is proved by the segregation of adenine-requiring cultures from the crosses with the $\mathrm{AD}_{2}^{+}$strain. That the suppressor is linked to a lethal mutation is suggested by the equal numbers of adenine requirers and non-requirers segregating. If the nonviability was a random event or was due to an unlinked lethal mutation, the segregation expected is $3 A D^{+}: 1 \mathrm{ad}^{-}$. Summing over the two segregations, there are $14 A D^{+}$and $16 a^{-}$cultures; $\chi_{3 A D: 1 a d}^{2}>12 ; \mathrm{P}<0.01$.) The segregation of the second cross $234 / 17 a \times 228 / 1 d$, is similar but less conclusive. However, this diploid was heterozygous for $h i_{2,1}$, and it segreagted $9 \mathrm{hi}^{-}$and $1 \mathrm{HI}^{+}$cultures, an indication of linkage between the lethal and $\mathrm{hi}_{2}^{+}$genes. In other words, the crosses seem to indicate that the original suppressor, $S_{Q_{2}}$, is still present in these two haploid strains and that it is responsible for the adenine independent phenotype. It is also still associated with a gene which, in segregating from the diploids formed, behaves as a lethal.

In order to confirm this interpretation, one of the two adenine independent haploids, 234/17a, was crossed with another strain, 233/12b $=\alpha, a d_{2,1}^{0}$, $h i_{2,1}$. The diploid was adenine and histidine independent. One hundred asci were dissected. In all but three, only two or fewer spores germinated to form viable colonies, all being adenine requirers (table 4, line 9). In the three exceptional tetrads, three spores germinated. In one, all three cultures were adenine dependent $\left(a d_{2}^{-}\right)$. In the other two, two spore-cultures were $a d^{-}$and one $A D^{+}$. One of these $\mathrm{AD}^{+}$cultures was diploid. The segregation of $h i_{2}$ and of mating-type in all the half-tetrads recovered was:

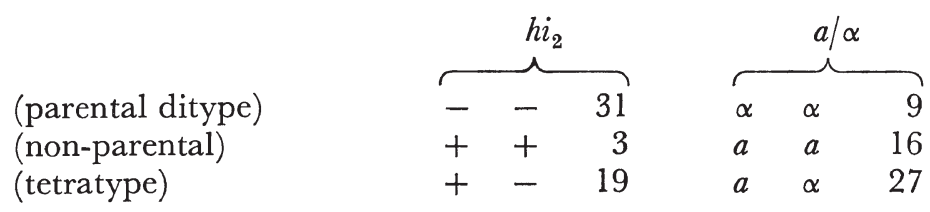

Clearly, the lethal mutation is again segregating, it is very closely linked to the suppressor since from only one of 400 spores tested did a viable adenine-independent culture grow; it is linked to $h i_{2}$ (there is a significant excess of parental ditypes, recombination is 28.7 per cent.) and it is centromere linked, since there is an excess of ditypes of the loosely centromerelinked mating-type gene $\left(\chi_{2 D=T}^{2}=5 \cdot 13 ; \mathrm{P}<0.05\right)$. Thus, in two matings of viable adenine-independent haploids, diploids were formed from which a lethal mutation segregated, and it is the same lethal that segregates in the original suppressed strain and in the diploids from which these two exceptional haploids were derived. Therefore, whatever the reason for the 
viability of the two suppressor-bearing strains, it cannot be that the lethal mutation has been separated from suppressor mutation by recombination, mutation or gene conversion.

This result was not, however, consistently repeated. In some crosses involving one of the exceptional adenine-independent cultures, 234/17a, and strains carrying super-suppressible mutant alleles, no lethal gene segregated. The results are shown in table 6. It is clear that in three crosses

TABLE 6

The germination of spores and the segregation of markers in three diploids formed by mating 234/17a $\left(\mathrm{n}=\mathrm{a}, \mathrm{ad}_{2}^{\mathrm{O}}, 1, \mathrm{se}_{1,1}, \mathrm{tr}_{1,1}, \mathrm{~S}_{\mathrm{Q}_{2}}\right)$ with various complementary strains

Number of tetrads in which so many spores germinated

\begin{tabular}{|c|c|c|c|c|c|c|c|c|c|c|c|c|}
\hline \multirow{2}{*}{$\begin{array}{c}\text { Diploid } \\
\text { no. }\end{array}$} & \multicolumn{5}{|c|}{ spores germinated } & & \multicolumn{6}{|c|}{ Segregation of markers (number of tetrads) } \\
\hline & 4 & 3 & 2 & 1 & 0 & & $a d_{2}^{0}, 1$ & $s e_{1}$ & $t r_{1,1}$ & $a r_{4,23}$ & $h i_{5,2}^{\circ}$ & $l y_{1}^{0}, 1$ \\
\hline \multirow[t]{5}{*}{249} & 9 & 1 & 0 & 0 & 0 & $4: 0$ & $*_{0}$ & 0 & 0 & 0 & 1 & 1 \\
\hline & & & & & & $3: 1$ & 0 & 0 & 0 & 1 & 4 & 2 \\
\hline & & & & & & $2: 2$ & 6 & 6 & 6 & 5 & 1 & 3 \\
\hline & & & & & & $1: 3$ & 0 & 0 & 0 & 0 & 0 & 0 \\
\hline & & & & & & $0: 4$ & 0 & 0 & 0 & 0 & 0 & 0 \\
\hline \multirow[t]{5}{*}{250} & 8 & 2 & 0 & 0 & 0 & $4: 0$ & 0 & 0 & 0 & 0 & 1 & 1 \\
\hline & & & & & & $3: 1$ & 0 & 0 & 0 & 0 & 4 & 7 \\
\hline & & & & & & $2: 2$ & $3 \dagger$ & 8 & 8 & 8 & 3 & 0 \\
\hline & & & & & & $1: 3$ & 4 & 0 & 0 & 0 & 0 & 0 \\
\hline & & & & & & $0: 4$ & 1 & 0 & 0 & 0 & 0 & 0 \\
\hline \multirow[t]{5}{*}{252} & 18 & 1 & 0 & 0 & 1 & $4: 0$ & 0 & 0 & not & 0 & not & 3 \\
\hline & & & & & & $3: 1$ & 0 & 0 & - & 0 & - & 11 \\
\hline & & & & & & $2: 2$ & 18 & 18 & - & 18 & - & 4 \\
\hline & & & & & & $1: 3$ & 0 & 0 & - & 0 & - & 0 \\
\hline & & & & & & $0: 4$ & 0 & 0 & 一 & 0 & - & 0 \\
\hline
\end{tabular}

* Only six tetrads tested.

$\dagger$ A second, non-suppressible, unlinked adenineless mutation is segregating.

Note - All the diploids were homozygous for $a d_{2}^{o},{ }_{1}$ and heterozygous for $S_{Q_{2}}$ and for the other markers shown; except for Diploid No. 252, which is homozygous wild-type at the $h i_{5}$ locus, and heterozygous for the super-suppressor $S_{Q_{5}}$.

germination is close to 100 per cent,, but also that a super-suppressor segregated, suppressing both the $a d_{2,1}^{0}$ allele, for which all the diploids were homozygous and the $h i_{5,2}^{\circ}$ and $l y_{1,1}^{\circ}$ alleles, for which they were heterozygous. The suppressor is $c$-linked, for of fourteen tetrads, thirteen showed ditype segregation of $\operatorname{tr}_{1,1}$ and the suppressor, and one a tetratype segregation $7 P, 6 \mathcal{N}, 1 T)$.

Thus it is observed that a super-suppressor, probably that originally isolated, $S_{Q_{2}}$, is responsible for the adenine independence of the two exceptional cultures arising from tetrads from zygote-rescued spores. In some crosses the super-suppressor is closely linked, as before, with a lethal mutation, but in other crosses involving the same super-suppressed haploid, the lethal character fails to operate, and the super-suppressor is recovered in viable haploid cultures. 


\section{(iv) The influence of $\psi$}

The third cross of table 6 is informative. Here, the haploid strain to which $234 / 17 a$ was mated carries another super-suppressor, $S_{Q_{5}}$. However, in this strain, $S_{Q_{5}}$ is inactive. As previously reported (Cox, 1965), the activity of $S_{Q_{5}}$ depends upon a cytoplasmic determinant, $\psi$. In $\psi^{+}$strains, $S_{Q_{5}}$ suppresses super-suppressible alleles, but $\psi^{-}$strains remain auxotrophic whether $S_{Q_{5}}$ is present or not. Diploids formed by mating $\psi^{+}$nd $\psi^{-}$haploids are $\psi^{+}$. Since $S_{Q_{5}}$ and $S_{Q_{2}}$, the super-suppressor and lethal mutation under discussion, were both isolated in the same diploid strain, it was expected that all segregants would be $\psi^{+}$and therefore that $S_{Q_{5}}$ would be active in the diploid and its haploid segregants. However, it is clear that, in the cross described in line three of table 6 , only one active super-suppressor is segregating. The presence of $S_{Q_{5}}$ among the adenineless segregants is readily demonstrated by mating them with $a d_{2,1}^{0}, \psi^{+}$strains. Any haploid carrying $S_{Q_{5}}$ then forms a diploid which is adenine independent, since $S_{Q_{5}}$ is active in this cytoplasmic background (i.e. $a d_{2}^{0}, 1, S_{Q_{5}}, \psi^{-}$(adenineless) $\times a d_{2}^{0}, 1, \psi^{+}$ (adenineless) $\rightarrow a d_{2,1}^{0} / a d_{2,1}^{0}, S_{Q_{5}} /+, \psi^{+}$(adenine independent). All the $a d^{-}$segregants from eighteen tetrads taken from this cross were cross-streaked with $a$ and $\alpha a d_{2,1}^{0}, \psi^{+}$strains. By this test, in fourteen tetrads $S_{Q_{5}}$ was found to be present, but inactive, in one of the two $a d^{-}$segregants; in one tetrad it was present in both of them and in three tetrads it was present in neither. The inactive $S_{Q_{5}}$ therefore segregates independently of the active suppressor.

All these adenine-requiring segregants were also cross-streaked with $a$ and $\alpha a d_{2,1}^{0}, S_{Q_{5}}, \psi^{-}$strains. All the diploids formed were adenine requirers, confirming that the diploid and its segregants were $\psi^{-}$.

By the same test, segregants from the cross $234 / 17 a \times 233 / 12 b$ (table 4 , line 9), in which the lethal phenotype was expressed, can be shown all to be $\psi^{+}$. The suppressor-carrying parent strain $234 / 17 a$ is common to both these crosses.

These results show:

1. that a super-suppressor, $S_{Q_{2}}$, appears to cause or to be linked tightly to a gene causing death in certain haploid strains;

2. that in other haploids, no death occurs due to this gene;

3. that those haploids in which the lethality is expressed segregate from diploids which are $\psi^{+}$;

4. that those which are viable are $\psi^{-}$; and

5. that when these $\psi^{-}$, viable, suppressed strains are crossed with other $\psi^{-}$strains, the suppressor segregates in a normal mendelian fashion, and no inviability is observed among the spores.

Since the original viable, suppressed strains arose among segregants from $\psi^{+}$diploids, it is presumed that the acquisition of viability is due to a mutation from $\psi^{+}$to $\psi^{-}$.

The role of the $\psi$ factor in determining the expression of lethality of $S_{Q_{2}}$ has been confirmed in a number of crosses.

One set of crosses was made to check that the observed effects were a direct result of the $\psi^{+} \rightarrow \psi^{-}$mutation. This mutation was first observed in three separate strains, carrying the $S_{Q_{5}}$ super-suppressor mutation (Cox, 1965). The $\psi^{+}$and $\psi^{-}$subcultures of two of these strains, 170/2c and $172 / 9 b$ were used as parents in crosses with haploids containing $S_{Q 2}$. The results 
are shown in table 4, lines 10-14. The crosses involving the three independent $\psi$ - reversions show good viability, with several tetrads in which all four spores germinated. Only one suppressor appeared to be active, since adenine dependence: independence segregated $2: 2$. An excess of ditypes of adenine requirement and $t r_{1,1}$ was found in each cross (diploid 273 gave $3 P, 7 \mathcal{N}, 0 T$; diploid 277 gave $2 P, 5 \mathcal{N}, 0 T$; diploid $278,5 P, 4 \mathcal{N}, 0 T$ ). This suggests that the suppressor expressed was the $c$-linked $S_{Q_{2}}$. It was shown that $S_{Q_{5}}$ was segregating, although unexpressed, by crossing the adenine-requiring segregants with $a d_{2,1}^{0} \psi^{+}$strains. Some of the diploids formed in this way were white, and adenine independent. It is concluded that the diploids and all the segregants are $\psi^{-}$. This indicates that the $S_{Q_{2}}$-carrying parent strain was also $\psi^{-}$.

The crosses involving the non-revertant, $\psi^{+}$originals of these strains do not show the clear-cut recessive lethal segregation expected. In one case (diploid 276) this turned out to be because of a $S_{Q 2}^{+}$revertant clone present in the mating mixture from which the tetrads derived. In the other, one spore culture in each of the four tetrads in which three spores germinated grew, but only slowly. Plate I shows the tetrads derived from diploids 272 and 273 , illustrating the $\psi$ effect on the expression of lethality.

In both 272 and 276 tetrads, $S_{Q_{5}}$ segregated and was expressed as a suppressor, confirming that both diploids and segregants were $\psi^{+}$.

An attempt was also made to show that the determinant of the expression of lethality by $S_{Q_{2}}$ was, like $\psi$, not inherited in a mendelian pattern. A cross was made between a $\psi^{+}$and a $\psi^{-}$strain, and tetrads dissected out. All the cultures from three of these tetrads were mated with viable haploid strains containing $S_{Q_{2}}$. The results are shown in table 4, lines 15-26. With one or two exceptions, $S_{Q_{2}}$ plainly behaves as a recessive lethal in all these crosses. The crosses with the parent strains are shown in lines 27-30 of the same table.

Table 7 summarises the expression of the lethal character of $S_{Q 2}$ in $\psi^{+}$ and $\psi^{-}$strains. These include the following kinds of mating, described below. The carriers of $S_{Q 2}$ are of three kinds or classes:

I. Segregant spores of the original suppressed diploid rescued by mating, as described in section (l) above (seven strains).

II. Exceptional viable suppressed haploids (ten strains).

III. Descendants of these exceptions obtained from crosses between them and $\psi^{-}$strains (seven strains).

Cells of the first class are expected to be $\psi^{+}$, those of the last two, $\psi^{-}$. Their mating partners have been:

Class I crossed with $\psi^{+}(228 / 3 d, 198 / 6 c)$.

Classes II and III crossed with:
A. segregants of the original diploid, Q2-expected to be $\psi^{+}$;
B. the original $\psi^{+}$and $\psi^{-}$strains;
C. parents and relations of these original strains-expected to be $\psi^{+}$;
D. segregants from $\psi^{-} \times \psi^{-}$matings - expected to be $\psi^{-}$;
E. segregants from $\psi^{+} \times \psi^{-}$matings - expected to be $\psi^{+}$;
F. JM32-found to be $\psi^{-}$(Cox, 1965);
G. sibs of Class (III) carriers-expected to be $\psi^{-}$.

Some matings, therefore, are expected to give rise to $\psi^{+}$diploids. These are all those involving Class (I) carriers of $S_{Q_{2}}$, and all Class (II) and (III) 
carriers mated with types A, C, E and $\psi^{+}$forms of type B. Segregations from these diploids are recorded in the top half of the table. The other

\section{TABLE 7}

A summary of the survival of spores in tetrads from all the diploids analysed in this study in which $\mathrm{S}_{\mathrm{Q}_{2}}$ mutation was segregating. The table includes notes on those segregations which are exceptions to the general rule that $\mathrm{S}_{\mathrm{Q}_{2}}$ is lethal in $\psi^{+}$strains but not in $\psi^{-}$strains. The survival of spores in these exceptions is not recorded in the main body of the table, but in the notes below. Data already given in table 1 is excluded altogether

\begin{tabular}{|c|c|c|c|c|c|c|c|c|}
\hline \multirow[b]{2}{*}{$\begin{array}{l}\text { Source } \\
\text { of } S_{Q 2}{ }^{*}\end{array}$} & \multirow[b]{2}{*}{$\begin{array}{l}\text { Type of } \\
\text { mating* }\end{array}$} & \multirow[b]{2}{*}{$\begin{array}{l}\text { No. of diploids } \\
\text { analysed }\end{array}$} & \multicolumn{5}{|c|}{$\begin{array}{l}\text { Number of tetrads with } \\
\text { so many spores } \\
\text { germinating }\end{array}$} & \multirow[b]{2}{*}{$\begin{array}{c}\text { No. of } \\
\text { exceptions }\end{array}$} \\
\hline & & & 4 & 3 & $\overbrace{2}$ & 1 & $\widetilde{0}$ & \\
\hline \multicolumn{9}{|c|}{ (i) $\psi^{+}$Diploids: } \\
\hline I & - & 7 & 1 & 6 & 48 & 13 & 16 & none \\
\hline \multirow[t]{3}{*}{ II } & A & 2 & 0 & 3 & 62 & 10 & 35 & none \\
\hline & C & 8 & 0 & 3 & 33 & 9 & 5 & $3^{a}$ \\
\hline & $\mathrm{E}$ & $\begin{array}{c}(5 \text { recorded }) \\
7 \\
(5 \text { recorded })\end{array}$ & 0 & 3 & 33 & 4 & 1 & $2^{b}$ \\
\hline \multirow[t]{4}{*}{ III } & A & 2 & 0 & 1 & 18 & 0 & 0 & none \\
\hline & B & 2 & 0 & 4 & 9 & 2 & 2 & none \\
\hline & C & 4 & 0 & 4 & 22 & 3 & 5 & none \\
\hline & $\mathrm{E}$ & $\begin{array}{c}14 \\
\text { (12 recorded) }\end{array}$ & 0 & 0 & 100 & 13 & 7 & $2^{c}$ \\
\hline \multicolumn{2}{|c|}{ Total $\psi^{+}$Diploids } & $\begin{array}{c}46 \\
\text { (39 recorded) }\end{array}$ & 5 & 29 & 304 & 54 & 74 & 7 \\
\hline \multicolumn{9}{|c|}{ (ii) $\psi^{-}$Diploids: } \\
\hline II & D & 9 & 52 & 6 & 4 & 1 & 18 & $1^{d}$ \\
\hline \multirow[t]{4}{*}{ III } & D & 6 & 51 & 6 & 4 & 2 & 4 & none \\
\hline & B & 3 & 26 & 1 & 0 & 1 & 2 & none \\
\hline & $G$ & 3 & 25 & 2 & 0 & 1 & 2 & none \\
\hline & F & 1 & 10 & 0 & 0 & 0 & 0 & none \\
\hline \multicolumn{2}{|c|}{ Total $\psi^{-}$Diploids } & (21 recorded) & 164 & 15 & 8 & 5 & 26 & 1 \\
\hline
\end{tabular}

(iii) Notes on exceptional segregations:

a Matings of three viable suppressed haploid strains from a $234 / 17 a \times \psi^{+}$mating. All segregants were $\psi^{+}$.

$a_{1} .292 / 3 a \times \psi^{+}:$

$a_{2} . \quad 292 / 5 a, 292 / 7 a \times \psi^{+}$:

${ }^{b}$ Suppressed segregants from $a_{2}$ above. $364 / 7 c, 366 / 4 c \times \psi^{+}$:

$\begin{array}{rrrrr}0 & 1 & 8 & 1 & 0 \\ 18 & 0 & 2 & 0 & 0 \\ 10 & 6 & 4 & 0 & 0\end{array}$

- Most $S_{Q_{2}}$ segregants grew very slowly (see table 4, lines 22 and 23). $367 / 2 c \times \psi^{+}: \quad 4 \begin{array}{lllll} & 5 & 9 & 0 & 1\end{array}$

${ }^{d} S_{Q_{2}}$ behaved as a recessive lethal, although the segregants were all $\psi^{-}$. $234 / 17 a \times \psi^{-}$:

$\begin{array}{lllll}0 & 1 & 13 & 2 & 1\end{array}$

* An explanation of the symbols in these columns is given in the text. The origin of the strain $234 / 17 a$ is shown in table 4 , line 4 , and is also mentioned in the text.

matings are expected to give rise only to $\psi$ - diploids, and segregations from them are recorded in the bottom half of the table.

If the segregations from the $\psi^{+}$diploids are considered first it will be seen that among 437 tetrads recorded from 40 diploids, only two spores germinated in 304 ( 70 per cent.) of them, and in only 34 ( 8 per cent.) did more than 
two germinate. The lethality was always, in the $2: 0$ segregations, linked with the $S_{Q_{2}}$ suppressor. Thus the overall pattern is that expected if $S_{Q_{2}}$ is a recessive lethal mutation, with a minor fraction of exceptions. These will be described below.

The segregations from $\psi^{-}$diploids show no sign of the lethal phenotype of $S_{Q_{2}}$. Among 218 tetrads from 22 diploids, 164 (75 per cent.) gave rise to four viable cultures. The viability of $S_{Q_{2}}$ haploids was no different from that of $S_{Q 2}^{+}$. There was one exception (table 7, footnote $d$ ).

The exceptions among $\psi^{+}$diploids to be considered are, firstly, those tetrads in which three or more spores gave rise to viable cultures. Some of these were trivial, in that the extra culture did not carry the $S_{Q_{2}}$ suppressor gene, and therefore would not be expected to be inviable.

Others were suppressed. Almost invariably, such cultures were very slow to germinate and grow, giving rise to minute colonies compared to their sibling spore-cultures. However, regardless of their vigour, they all proved on crossing, to be $\psi^{-}$, while their sibs remained $\psi^{+}$. The occurrence of these kinds of exceptional segregant is important in relation to the effects of the $\psi$ factor and the reasons for the lethal phenotype.

Secondly, one $\psi^{+}$diploid, 292 (footnotes $a$ and $b$, table 7) produced a number of normally viable suppressed haploid strains. All the nonsuppressed sibs of these cultures were $\psi^{+}$. One of the viable suppressed segregants gave rise to a characteristic recessive-lethal segregation on crossing to a $\psi^{+}$strain (table 7 , footnote $a_{1}$ ). Two others, however, showed no lethality of the suppressor in such a cross (footnote $a_{2}$ ), nor in second-generation crosses with $\psi^{+}$strains (footnote $b$ ). All the non-suppressed sibs of these second and third generation, viable, suppressed segregants were shown to be $\psi^{+}$. It must be concluded that, in all likelihood, these $S_{Q_{2}}$-carrying segregants are also $\psi^{+}$, but not fatally affected by the lethal gene. At present, the best explanation for this exceptional diploid is that a dominant modifying mutation has occurred which negated the lethal effects of $S_{Q_{2}}$, in the original haploid and in segregants from crosses with it, without affecting the segregation of the $\psi^{+}$factor.

The single exceptional segregation among $\psi$ - diploids (table 7 , footnote $d$ ) is still unexplained. In a later repeat of this cross, germination was 95 per cent. $(8-2-0-0-0)$.

\section{(v) Behaviour of $\mathrm{S}_{\mathrm{D}}$}

$S_{Q_{2}}$ was found to be closely $c$-linked and linked to $h i_{2}$. This puts it very close to the super-suppressor $S_{D}$ originally isolated by Hawthorne and Mortimer (1963). The identity of the two has not been established by a cross, but it has been found that $S_{D}$ is also a recessive lethal in $\psi^{+}$and not in $\psi^{-}$ strains (table 4, lines 31-35).

\section{(vi) The isolation of more recessive lethal super-suppressors}

A small search was conducted to explore the occurrence and distribution of lethal super-suppressors in yeast. A $\psi^{+}$diploid strain was constructed having the following genotype:

$$
2 n=\frac{a d_{2,1}^{0}}{a d_{2,1}^{o}}, \frac{h i_{5,2}^{\circ}}{+}, \frac{l y_{1,1}^{o}}{l y_{1,1}^{o}}, \frac{h i_{2,1}}{+}, \frac{t r_{1,1}}{+}, \psi^{+} .
$$


Cells were plated on YC medium, and separate suspensions made of thirty-two colonies which grew. These suspensions were separately spread on YNB plates, and the plates irradiated with $1000 \mathrm{ergs} / \mathrm{mm} .^{2}$ light at $260 \mathrm{~nm}$. A single revertant colony was picked from each plate, each culture sporulated, and tetrads dissected. The results of the tests for segregations of the various markers are summarised in table 8 . The suppressors are identified as alleles of $S_{D}\left(S_{Q_{2}}\right)$ if they show significant linkage with both the $h i_{2}$ locus and the centromere, using $t r_{1,1}$ as a marker of centromere segregation.

Of the thirty-two revertants of independent origin:

2 could not be tested because they failed to sporulate;

1 showed an independent reversion of the $l y_{1}$ requirement and may not, therefore, be due to a super-suppressor mutation;

2 turned out still to require lysine: they may have grown originally as a result of some cross-feeding on the selection plate;

16 were super-suppressors which showed no loss of viability, and no indication of linkage to the $h i_{2}$ locus;

I No. 26, segregated a recessive lethal independently of the supersuppressor mutation. The suppressor but not the lethal phenotype, in this strain is linked to $h i_{2}$, but probably not to the centromere. It may or may not be allelic to $S_{D}$ : an inversion of the region could account for the data, which is too scanty to indicate whether $h i_{2}$ is significantly more closely $c$-linked than usual. Another suppressor, $S_{6}$ is known, distal and linked to $h i_{2}$ (Hawthorne and Mortimer, 1968);

1 reversion No. 28, is due to a super-suppressor which shows a reduced viability, but is not linked to either a centromere or the $h i_{2}$ locus;

5 reversions Nos. 22, 23, 24, 27 and 30, are due to suppressors which, since they show significant $(\mathrm{P}<0.05>0.0 \mathrm{I})$ linkage to $h i_{2}$, may be allelic with $S_{D}$. Only one, No. 27, shows any reduction in viability;

4 by their close $c$-linkage and highly significant $(\mathrm{P}<0.0 \mathrm{l})$ linkage to $h i_{2}$, either in coupling or repulsion, are likely alleles of $S_{D}$. Two are recessive lethals (Nos. 14 and 32) and two have a very greatly reduced viability in haploids (Nos. 15 and 31 ).

From these results we may conclude that recessive lethal super-suppressors do recur; that the only locus which has shown complete lethality in haploids is the $S_{D}$ locus; that it is possible, however, that alleles of $S_{D}$ may occur which are not lethal or show merely a very reduced viability and that at least one other super-suppressor (revertant No. 28) is associated with a very reduced viability, though whether by linkage or by gene action is not shown.

\section{(vii) Reversions of $\mathrm{S}_{\mathrm{Q}^{2}}$}

Six independent reversions of the $S_{Q_{2}}$ allele of $S_{D}$ to amber-specific suppression have been isolated in a haploid, $\psi^{-}$strain. That they are due to mutations of the $S_{Q_{2}}$ mutant locus itself and not to mutations at other loci has been demonstrated by complementation and recombination analyses. All six have been mated with $\psi^{+}$strains and asci dissected. Germination was found to be normal in all six amber versions of $S_{Q_{2}}$ (in 37 tetrads, all 
TABLE 8

A summary of the tetrad analyses of thirty-two adenine-and lysine-independent revertants of a $\psi^{+}$diploid homozygous for $\mathrm{ad}_{2}^{0}, 1$ and $\mathrm{ly}_{1}^{0}, 1$ and heterozygous for $\mathrm{hi}_{2}$ and the c-linked marker, $\mathrm{tr}_{1,1}$

\begin{tabular}{|c|c|c|c|c|c|c|c|c|c|c|c|}
\hline \multirow[b]{3}{*}{$\begin{array}{c}\text { Revertant } \\
\text { number }\end{array}$} & \multirow{2}{*}{\multicolumn{5}{|c|}{$\begin{array}{l}\text { Number of tetrads } \\
\text { in which so many } \\
\text { spores germinated }\end{array}$}} & \multirow{2}{*}{\multicolumn{2}{|c|}{$\begin{array}{c}\text { Number of } \\
\text { Segregants } \\
\text { of } \\
\text { phenotype }\end{array}$}} & \multicolumn{3}{|c|}{ Linkage } & \multirow[b]{3}{*}{ Notes } \\
\hline & & & & & & & & & & S-centromere & \\
\hline & 4 & _- & 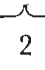 & - & $\overbrace{0}$ & $\overparen{a d}$ & $A D^{+}$ & S-lethal & $\mathrm{S}-h i_{2}$ & $\overbrace{\mathrm{DT}}^{\mathrm{TT}}$ & \\
\hline 1 & 10 & 1 & 0 & 3 & 6 & 24 & 22 & - & n.s. & $7: 3$ & A \\
\hline 2 & 2 & 0 & 1 & 2 & 5 & 4 & 4 & - & n.s. & $1: 1$ & \\
\hline 3 & 1 & 3 & 0 & 0 & 6 & 6 & 6 & $\longrightarrow$ & n.s. & - & \\
\hline 4 & 6 & 1 & 1 & 0 & 2 & 17 & 20 & - & n.s. & - & \\
\hline 5 & & & & & & too & $w$ asci & & & & \\
\hline 6 & 7 & 1 & 2 & 0 & 0 & 14 & 14 & - & 0 & - & \\
\hline 7 & 0 & 1 & 3 & 0 & 6 & 5 & 3 & n.s. & n.s. & - & \\
\hline 8 & 0 & 0 & 1 & 2 & 7 & 3 & 1 & n.s. & n.s. & - & \\
\hline 9 & 7 & 0 & 1 & 0 & 2 & 14 & 14 & - & 0 & $3: 3$ & \\
\hline 10 & 0 & 0 & 6 & 1 & 3 & 1 & 4 & n.s. & 0 & - & \\
\hline 11 & 6 & 2 & 1 & 0 & 1 & 14 & 10 & - & n.s. & $1: 4$ & \\
\hline 12 & 9 & 2 & 0 & 4 & 5 & 23 & 19 & - & 0 & $6: 2$ & \\
\hline 13 & 7 & 2 & 1 & 0 & 0 & 14 & 14 & - & o & $0: 7$ & \\
\hline 14 & 0 & 3 & 47 & 9 & 1 & 112 & 0 & complete & $++^{c}$ & $38: 2$ & B \\
\hline 15 & 0 & 15 & 15 & 8 & 11 & 57 & 9 & ++ & $++^{c}$ & $22: 5$ & B \\
\hline 16 & 6 & 1 & 2 & 1 & 0 & 12 & 12 & - & 0 & $3: 3$ & \\
\hline 17 & 0 & 0 & 4 & 5 & 1 & 2 & 6 & o & n.s. & $2: 2$ & \\
\hline 18 & 7 & 2 & 1 & 0 & 0 & 17 & 11 & - & 0 & $0: 6$ & \\
\hline 19 & 4 & 4 & 0 & 0 & 2 & 16 & 11 & - & o & $22: 1$ & \\
\hline 20 & 5 & 3 & 1 & 0 & 1 & 10 & 10 & - & 0 & - & A \\
\hline 21 & & & & & & & asci & & & & \\
\hline 22 & 6 & 4 & 2 & 1 & 7 & 17 & 15 & - & + & $2: 1$ & $\mathrm{C}$ \\
\hline 23 & 6 & 2 & 0 & 1 & 7 & 13 & 11 & - & $+r$ & $3: 1$ & C \\
\hline 24 & 2 & 0 & 1 & 3 & 4 & 7 & 6 & - & $+^{r}$ & - & $\mathrm{C}$ \\
\hline 25 & 6 & 3 & 0 & 0 & 1 & 10 & 10 & - & o & $2: 3$ & \\
\hline 26 & 0 & 0 & 42 & 10 & 8 & 45 & 39 & oo & $++^{r}$ & $6: 7$ & $\mathrm{D}$ \\
\hline 27 & 0 & 6 & 2 & 2 & 0 & 15 & 5 & + & $+c$ & - & C \\
\hline 28 & 2 & 13 & 21 & 15 & 1 & 45 & 12 & + & 00 & $5: 6$ & $\mathbf{E}$ \\
\hline 29 & 7 & 3 & 0 & 0 & 0 & 12 & 12 & - & 0 & $2: 4$ & $F$ \\
\hline 30 & 0 & 1 & 6 & 1 & 2 & 9 & 6 & n.s. & $t^{r}$ & $3: 2$ & $\mathrm{C}$ \\
\hline 31 & 0 & 10 & 38 & 5 & 7 & 92 & 8 & ++ & $++^{r}$ & $33: 9$ & B \\
\hline 32 & 0 & 0 & 14 & 31 & 10 & 58 & 0 & complete & $++^{r}$ & $8: 2$ & B \\
\hline
\end{tabular}

Symbols: +, or ++ : linkage indicated at the 5 per cent. or 1 per cent. significance levels, respectively. " $\mathrm{r}$ " or " $\mathrm{c}$ " indicate whether the gene is in coupling or in repulsion with $h i_{2,1}$. o, or oo: non-linkage is indicated at the 5 per cent. or 1 per cent. levels, respectively. The null hypothesis is that $S_{D}$ recombines with $h i_{2}$ in 30 per cent. of single-strands. n.s. = not significantly linked.

Notes:

Types found Number

$\begin{array}{lrl}\text { A } & 2 & \text { All lys. Possibly not a suppressor } \\ \text { B } & 4 & \text { A recessive lethal } S_{D} \text {, or an allele of } S_{D} \text { with very reduced viability. } \\ \text { C } & 5 & \text { A possible non-lethal allele of } S_{D} . \\ \text { D } & 1 & \begin{array}{l}\text { The suppressor was non-lethal, linked to } h i_{2}(12 \cdot 5 \text { per cent. recom- } \\ \text { binants }) \text { but not } c \text {-linked. The lethal mutation is independent of }\end{array} \\ & & \begin{array}{l}\text { the suppressor, of } h i_{2} \text { and the centromere. } \\ \text { E }\end{array} \\ \text { F } & 1 & \text { A suppressor with very reduced viability, not an allele of } S_{D} . \\ \text { G } & 1 & \text { Lys } \rightarrow \text { LYS independently reverted. } \\ \text { H } & 16 & \text { Viable suppressors, not alleles of } S_{D} .\end{array}$


four spores germinated; in 37 tetrads, three germinated; in 4, two germinated; in 5, only one and in 7 tetrads, no spores germinated; the overall percentage germination is 75 per cent.). In other words, the amber form of $S_{Q_{2}}$ is not a recessive lethal when selected in $\psi^{-}$strains and transferred to $\psi^{+}$cytoplasm. No attempt has yet been made to select amberspecific versions of $S_{D}$ or $S_{Q 2}$ in $\psi^{+}$diploid strains.

\section{Discussion}

A super-suppressor which is lethal to most haploid cells has been isolated in a diploid strain of yeast. The lethality, but not the suppressor activity, is modified when the suppressor is included in yeast strains of the " $\psi^{-}$" type. " $\psi^{+} "$ and " $\psi^{-}$" strains are differentiated by their ability or not to express the activity of another super-suppressor, $S_{Q_{5}}$ (Cox, 1965). The $\psi^{ \pm}$ difference is inherited cytoplasmically.

Before going on to discuss the possible reasons for this occurrence, it is worth noting some other effects of the $\psi^{+} / \psi^{-}$character difference on cells. In cells with no super-suppressors, the $\psi^{+}$or $\psi^{-}$character makes no difference to the growth of the cultures under various culture conditions, nor to the expression of genes, nor to their sensitivity to ultraviolet light, as measured by mutation or survival. Nor does the $\psi$ status have any influence on the expression of two Class III super-suppressors $\left(S_{\eta}\right.$ and $S_{\theta}$, Gilmore, 1966). That is, alleles suppressible by these suppressors continue to be suppressed whether the strains are $\psi^{+}$or $\psi^{-}$.

However, if a Class I super-suppressor is present, the $\psi$ status may have an effect. Two of these have already been noted: (I) the Class I supersuppressor $S_{Q_{5}}$ does not suppress any suppressible allele in $\psi^{-}$strains; (2) many specifically ochre-suppressing alleles of the $S_{D}$ locus are lethal in haploid $\psi^{+}$strains, but not lethal in $\psi^{-}$strains, even though they continue to suppress ochre mutations.

A third effect should also be briefly described. Four other Class I, set 1 super-suppressors, $S_{\alpha}, S_{\beta}, S_{\gamma}$, and $S_{\delta}$ were provided by Dr Gilmore (Gilmore, 1966). These were mated with $\psi^{+}$and $\psi^{-}$strains. All zygotes from matings with $\psi^{-}$grew and sporulated, and in all of them the $a d_{2,1}^{0}$ mutation and other ochre mutations were suppressed. However, of forty-six zygotes formed between cells of these cultures and cells of $\psi^{+}$strains, only one grew normally. Most of the others (twenty-three) formed only minute colonies ( $200 \mu \mathrm{m}$ after six days' growth: single zygotes normally form colonies $1000 \mu \mathrm{m}$ in diameter after two days). Sixteen zygotes lysed immediately, or after a few divisions and the remainder grew only slowly. None of the cultures which grew was able to sporulate. A similar effect had been noted earlier with revertants of a $\psi^{-}$strain JM32. $\left(n=a, a d_{2,1}^{0}, h i_{5,2}^{\circ}, l y_{1,1}^{o}, \arg _{4,23} \psi^{-}\right.$.) These were selected after UV treatment of individual colonies re-spread on YNB supplemented with arginine and lysine. They were therefore simultaneously adenine and histidine independent due, presumably, to super-suppressor mutations of Gilmore's Class 1. Twenty-seven revertants were mated with a $\psi^{+}$strain and fifty-four zygotes isolated by micromanipulation. Seven grew normally, ten grew slowly, thirty-one formed colonies of 100 cells or fewer after six days and six lysed. The strain of $S_{D}$ provided by Dr Gilmore also tends to form non-viable zygotes in $\psi^{+}$crosses, but the effect is not so extreme.

We thus have a complex of effects of the $\psi$ factor in combination with 
Class 1 super-suppressors which can best be summarised in the form of a table (table 9).

In considering the association of a recessive lethal phenotype with alleles of $S_{D}$ three general explanations occur.

I. A simultaneous, closely linked mutation occurs in a "vital" gene. This may take the form of a second, coincidental, point mutation, or the lethal and suppressor phenotypes may be due to a single deletion.

2. The mutation giving the suppressor phenotype, through a structural rearrangement, affects the behaviour of the neighbouring centromere.

3. The suppressor phenotype itself affects the viability of the cell. There is also the possibility that the suppressor is lethal because it is due to a mutation in a unique t-RNA species.

\section{TABle 9}

A summary of the effect of the $\psi$ factor on various super-suppressors in haploid and diploid strains of yeast

\begin{tabular}{|c|c|c|c|c|}
\hline \multirow[b]{2}{*}{ Suppressor } & \multicolumn{2}{|c|}{$\psi^{+}$} & \multicolumn{2}{|c|}{$\psi^{-}$} \\
\hline & $n$ & $2 n$ & $n$ & $2 n$ \\
\hline $\begin{array}{l}S_{Q 5} \\
S_{D}, S_{Q_{2}} \\
\quad \text { (ochre) }\end{array}$ & $\begin{array}{l}\text { ochre } \\
\text { lethal }\end{array}$ & $\begin{array}{l}\text { ochre } \\
\text { ochre }\end{array}$ & $\begin{array}{l}\text { nil } \\
\text { ochre }\end{array}$ & $\begin{array}{l}\text { nil } \\
\text { ochre }\end{array}$ \\
\hline $\begin{array}{l}S_{\alpha, \beta, \gamma, \delta} \\
\text { and Ciass I } \\
\text { (ochre) }\end{array}$ & ? & lethal & ochre & ochre \\
\hline$S_{Q_{2}}$ (amber) & amber & amber & amber & amber \\
\hline
\end{tabular}

The possibility of coincident, linked, point mutations is rendered unlikely by the following observations.

1. With all six likely repetitions of the ochre-suppressing mutation at the $S_{D}$ locus, a recessive lethal or sub-lethal phenotype was associated.

2. In tetrad analysis, a number of haploid cultures were obtained in which the lethal phenotype had been lost and the suppressor phenotype retained. This could have been due to mutation or recombination separating determinants of the two phenotypes. However, further analysis showed that in every case but one, the recessive lethal phenotype was restored when the suppressed haploids were crossed to $\psi^{+}$strains. One spore culture could be interpreted as being due to such a separation of the two phenotypes, but other interpretations are also possible.

3. Six independently isolated reversions of $S_{Q_{2}}$ to an amber-specific suppressor were accompanied by a loss of the recessive lethal phenotype. The frequent recurrence of such an event is unlikely if it requires the simultaneous reversion of two point mutations or, indeed, the reversion of a deleted region.

The second possibility, that a structural rearrangement leads both to the suppressor phenotype and the derangement of centromere function would require that this derangement did not affect centromere behaviour in diploid mitosis, since the suppressor is stably inherited in diploids; it has no great effect on meiosis, since the suppressor can, in most cases, be recovered from haploid spores by " rescue matings", and did not affect it in $\psi^{-}$strains.

Either of these explanations is conceivable if a rather unconventional idea of the nature of super-suppressor mutations is accepted. However, since it 
is reported that eight Class 1 super-suppressors are genes which cause the insertion of tyrosine at UAA codons in messenger RNA (Gilmore et al., 1968; Sherman, Stewart, Parker, Putterman, Agrawal and Margoliash, 1970), it seems reasonable to suppose that they, like the $\mathrm{SU}_{\mathrm{III}}$ suppressor in $E$. coli, are due to base-substitutions in the anti-codon regions of genes determining the structure of tyrosine-accepting t-RNA species (Goodman, Abelson, Landy, Brenner and Smith, 1968). Hawthorne (1969b) presents evidence and arguments why $S_{D}$ should also be the result of mutations affecting a single base-pair in the anti-codon of tyrosine-accepting t-RNA's. If this is true, then an explanation of the properties of Class l super-suppression described here must be found in terms of gene action, that is of the effect of suppression itself.

This evidence also confirms that $S_{D}$ is not unique, but one of a number of genes determining tyrosine-accepting t-RNA species. If it has a unique function, it cannot be its amino-acid specificity. Recently, Soll and Berg (1969) reported a recessive lethal amber suppressor in $E$. coli which appeared to be due to a mutation in a t-RNA ${ }^{g l n}$ gene that is not unique. They suggested that the lethality might be owed to the major role normally played by the t-RNA specified by this gene in protein synthesis. Such a situation could explain the lethality of $S_{D}$ in haploid yeast. However, unlike the su7 mutation, $S_{D}$ does not appear to be a very efficient chain termination suppressor. Sherman et al. (1970) have found that Class I super-suppressors permit the completion of $i s o$-1-cytochrome $c$ protein from ochre-stopped $c y_{1}$ genes with at most 5 per cent. efficiency. As in E. coli, amber suppressors are more efficient. The discrepancy, it was originally suggested (Brenner, Stretton and Kaplan, 1966) could be a requirement of survival if the ochre codon were the normal chain-terminating codon: too efficient a misreading would have debilitating effects on normal protein synthesis. No such restriction need operate on the efficiency of amber suppression.

However, the source of the inefficiency is not understood. In $E$. coli it may be intrinsic, a property of the anticodon.

Amber and ochre alleles of a number of $E$. coli suppressors exist (Ohlson, Strigini and Beckwith, 1968; Person and Osborn, 1968), and the ochre suppressing alleles are derivable from amber by single base-pair mutagenesis. Ohlson et al. have been able to show that the change from amber to ochre suppression is accompanied in every case by reduction in the efficiency of suppression. Carbon and Curry (1969) have been able to show that missense-suppressing transfer RNA's have an intrinsic inefficiency in the sense that their rate of enzymic aminoacylation is altered.

An early suggestion by Brenner et al. (1966) was that the new ochrerecognising t-RNA in suppressed strains had to compete at the codon with an ochre-recognising t-RNA normally present and concerned in chaintermination. However, a study of the factors involved in chain termination in E. coli by Capecchi (1967), Scolnick, Tomkins, Caskey and Nirenberg (1968) and by Milman, Goldstein, Scolnick and Caskey (1969) has failed to demonstrate that t-RNA is involved at all. Indeed, the proteinaceous $\mathrm{R}$-factors appear to recognise all three nonsense codons equally well, $\mathrm{R}_{\mathbf{1}}$ being specific for UAA and UAG and $\mathrm{R}_{\mathbf{2}}$ for UAA and UGA. There do not appear to be any results from the in vitro assay system which suggest that competition for UAA might be greater than for the others.

Another way of achieving the inefficiency would be through an in- 
dependent gene modifying the mutant t-RNA, or, more likely, affecting its enzymatic modification. In $E$. coli this would have to be present in all strains used for genetic studies for, unless it were, it could not be transferred with every ochre suppressor in crosses, and it would therefore be impossible to transduce some ochre suppressors. The same restriction applies to yeast in which ochre suppressors would otherwise be lethal in half or more of the segregants from some crosses.

It is suggested that the phenomena described here are best explained if it is assumed that ochre suppression itself is potentially lethal when it becomes too efficient. The efficiency can be modified by secondary mutations and is also directly affected by, among other factors, the relative concentration of the mutant allele. Thus alleles of $S_{D}$ are lethal when present in a certain concentration per unit of protein being synthesised (in haploids) but not in half that concentration (in diploids). The effect of the $\psi$ status of the cell is to vary this efficiency, the efficiency, that is, of chain termination, which it does proportionately for all the tyrosine-inserting ochre suppressors. Let us suppose that in $\psi^{-}$strains, ochre suppressors only complete chains one-tenth as often as they do in $\psi^{+}$strains. Then considering each kind of suppressor in turn, the $S_{Q 5}$ mutant is efficient enough to be expressed as a suppressor in $\psi^{+}$strains, but at one-tenth efficiency, in $\psi^{-}$strains, no suppression is observable; $S_{Q_{2}}$ and other $S_{D}$ alleles are efficient enough to suppress at both levels. In $\psi^{+}$haploids, however, the efficiency is too great and therefore lethal, whereas at one-tenth the efficiency, in $\psi^{-}$strains, the cell's metabolism is unaffected; and similar differences occur in $\psi^{+}$and $\psi^{-}$ zygotes heterozygous for Class I, set I super-suppressors.

This interpretation stems principally from a consideration of the nature of the exceptions observed to the rule that $S_{Q 2}$ behaves as a recessive lethal. They do not arise as reversions of the original suppressor-lethal mutation. Rather they arise as the result of a mutational event in an independent determinant, of a kind which modifies the phenotype. In suitable crosses, the modifier can be removed and the original phenotype fully recovered. It would seem that in yeast, one or more such modifying activities is a necessary condition for the survival of cells having certain ochre-recognising t-RNA species.

In the examples described here, most of the mutations have occurred in the cytoplasmically inherited $\psi$ determinant. The exception described in a footnote of table 7 may be an example of a mendelian modifier affecting specifically the $S_{D}$ gene.

A detailed consideration of the mode of action of such modifiers is not due here. The activity of enzymes which alkylate or otherwise alter bases in t-RNA; activating enzyme specificity; ribosomal modifications which affect the efficiency of codon-anticodon recognition; m-RNA folding or the regulation of the rate of synthesis of t-RNA's; any of these could be involved. Whatever the mechanisms, one at least has to be reconciled with the mode of inheritance of the $\psi$ determinant.

\section{Summary}

1. This paper is an account of the isolation in a diploid strain of yeast of an ochre-mutation suppressor, $S_{Q_{2}}$, which is then segregated in meiosis as a recessive lethal. 


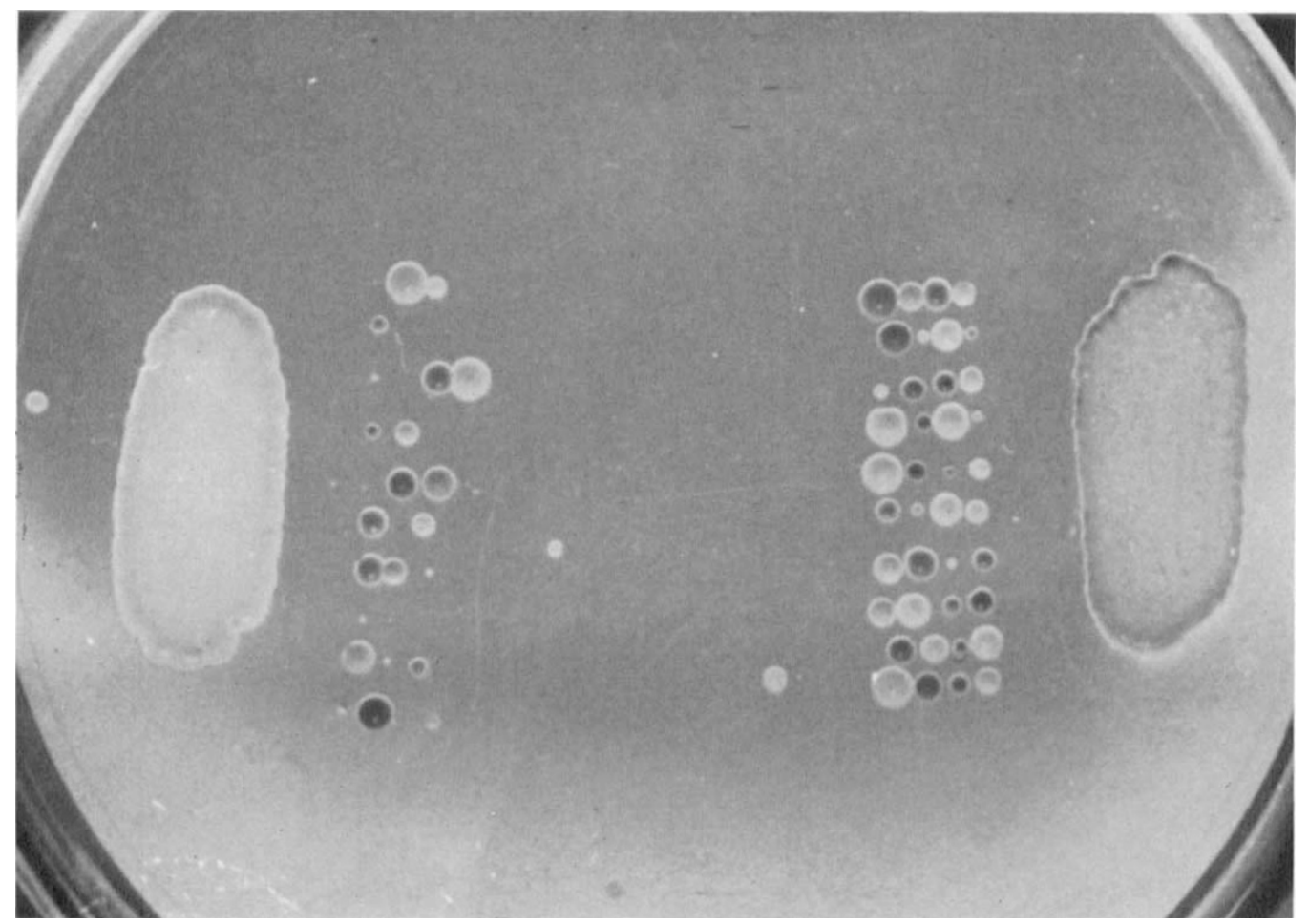

The effects of the $\psi$ factor on the expression of the lethal phenotype. The viable $S_{Q 2}$ haploid strain $249 / 5 b$ is crossed with $\psi^{+}$and $\psi^{-}$variants of strain $170 / 2 c$. Ten tetrads from each diploid have been dissected out. The $\psi^{+}$diploid, 272, is on the left, the $\psi$ - diploid, 273, on the right (table 4 , line 10 and 11 ). 
2. A genetic analysis has been carried out which demonstrates that it is the suppressor phenotype itself which leads to the death of haploid cells carrying the mutation.

3. The possibilities that the lethal phenotype is due to a coincident, closely linked mutation, or that both the suppressing and the lethal phenotypes are the result of a deletion affecting two loci have been considered.

4. They have been ruled out by showing that various independently isolated alleles of the suppressor (including, in these strains, the supersuppressor $S_{D}$, isolated by Hawthorne and Mortimer (1963)) are also recessive lethals, and that a number of independent reversions of the suppressor from ochre-specific to amber-specific suppression were accompanied by a loss of the lethal phenotype.

5. This interpretation is reinforced by the observation that the lethal phenotype can be lost without affecting the suppressor phenotype as a result of a modifying mutation.

6. The modifier is a cytoplasmically inherited determinent, $\psi$. The suppressor $S_{Q_{2}}$ is lethal in haploid $\psi^{+}$strains, but not so in $\psi^{-}$strains. The determinant has previously been identified by the fact that it modifies the activity of another ochre-specific super-suppressor, $S_{Q_{5}}$, though in that case, it is the suppressing phenotype which is altered; in $\psi^{-}$strains ochre mutations are not suppressed by $S_{Q_{5}}$, while they are in $\psi^{+}$strains.

7. The interpretation of these results takes into account certain other effects of the $\psi$ determinant on ochre-specific super-suppressors. It is that all the effects, lethality and suppressor activity, can be related to the efficiency of suppression, that is the frequency with which ochre codons are misread and chain termination prevented. When this efficiency is too great, normal protein synthesis is seriously affected, and lethality results. When it is too small, no suppression is observed.

8. The phenomena reported would result if the rate of ochre-misreading were higher in $\psi^{+}$strains than in $\psi^{-}$strains.

\section{REFERENCES}

BRenNer, s., stretton, A. O. w., And Kaplan, s. 1966. Genetic Code: the " nonsense" triplets for chain termination and their suppression. Nature, 206, 994-998.

CAPECCHI, M. 1967. Polypeptide chain termination in vitro: isolation of a release factor. Proc. natl. Acad. Sci. (Wash.), 58, 1144-1151.

CARBON, J., AND CURRY, J. B. 1969. Genetically and chemically derived missense suppressor transfer RNA's with altered enzymatic aminoacylation rates. F. molec. Biol., 38, 201216.

cox, B. s. 1965. $\Psi$, a cytoplasmic suppressor of super-suppressor in yeast. Heredity, 20, 505-521.

Cox, B. s., ANd bevan, E. A. 1962. Aneuploidy in yeast. Nere Phytol., 61, 342-355.

GILMORE, R. A. 1966. Ph.D. Thesis, University of California, Berkeley.

GILMORE, R. A. 1967. Super-suppressors in Saccharomyces cerevisiae. Genetics, 56, 641-658.

GILMORE, R. A., AND MORTIMER, R. K. 1966. Super-suppressor mutations in Saccharomyces cerevisiae. 7. molec. Biol., 20, 307-311.

GILMORE, R. A., STEWART, J. W., AND SHERMAN, F. 1968. Amino-acid replacements resulting from super-suppression of a nonsense mutant of yeast. Biochim. Biohpys. Acta, 161, 270272 .

GOODMAN, H. M., ABELSON, J., LANDY, A., BRENNER, s., AND SMITH, J. D. 1968. Amber suppression: a nucleotide change in the anticodon of a tyrosine transfer RNA. Nature, 217, 1019-1024.

HAWTHORNe, D. c. 1969a. Identification of nonsense codons in yeast. 7 . molec. Biol., 43, $71-75$. 
HAWTHORNe, D. c. 1969b. The selection of nonsense suppressors in yeast. Mutation Res., 7, 187-197.

haWthorne, D. C., AND MORTIMER, R. K. 1960. Chromosome mapping in Saccharomyces: centromere-linked genes. Fenetics, 45, 1085-1110.

hAWTHORNe, D. C., AND mortimer, R. K. 1963. Super-suppressors in yeast. Genetics, 48, 617-620.

HAWTHORNE, D. C., AND MORTIMER, R. K. 1968. Genetic mapping of nonsense suppressors in yeast. Genetics, 60, 735-742.

HURST, D. D., AND FOGEL, S. 1964. Mitotic recombination and heteroallelic repair in Saccharomyces cerevisiae. Genetics, 50, 435-458.

INGE-VEctomov, s. G. 1965. Suppressors of adenine requirement in yeast. Genetika, 2, 22-26. JOHNSTON, J. R., AND MORTIMER, R. K. 1959. Use of snail digestive juice in isolation of yeast spore tetrads. F. Bacteriol., 78, 292.

milman, G., GOldStein, J., scolnick, E., AND CASKeY, T. 1969. Peptide chain termination. III. Stimulation of in vitro termination. Proc. natl. Acad. Sci. (Wash.), 63, 183-190.

MORTIMER, R. K., AND HAWTHORNe, D. c. 1966. Genetic mapping in Saccharomyces. Genetics, $53,165-173$.

OHLSON, B. M., STRIGINI, P. F., AND BEGKWITH, J. R. 1968. Allelic amber and ochre suppressors. 7. molec. Biol., 36, 209-218.

PERSON, S., AND OSBORNE, M. 1968. The conversion of amber suppression to ochre suppression. Proc. natl. Acad. Sci. (Wash.), 60, 1030-1037.

SCHWEIZER, E., MACKECHNIE, C., AND HALVORSON, H. o. 1969. The redundancy of ribosomal and transfer RNA genes in Saccharomyces cerevisiae. 7. molec. Biol., 40, 261-227.

SCOLNICK, E., TOMPKINS, R., GASKeY, T., AND NIRENBERG, M. 1968. Release factors differing in specificity for terminator codons. Proc. natl. Acad. Sci. (Wash.), 61, 768-774.

SHERMAN, F., STEWART, J. W., PARKER, J. H., PUTTERMAN, G. J., AGRAWAL, B. L., AND MARGOLIASH, E. 1970. On the relationship of gene structure and protein structure of iso-1-cytochrome $c$ from yeast. Symp. Society for Experimental Biology, 24, 85-107.

SOLL, L., AND BERG, P. 1969. Recessive lethal nonsense suppressor in Escherichia coli which inserts glutamine. Nature, 223, 1340-1342. 